\title{
Pengembangan Sistem Informasi Terintegrasi untuk UPT PUSKESMAS
}

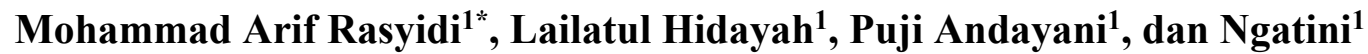 \\ ${ }^{1}$ Departemen Informatika, Universitas Internasional Semen Indonesia, Gresik. \\ *Corresponding Author \\ E-mail: mohammad.rasyidi@uisi.ac.id
}

\begin{abstract}
Abstrak
Pelayanan pada puskesmas sering dinilai kurang cepat. Proses administrasi yang masih manual ditambah lagi dengan jumlah pasien yang banyak membuat antrian menjadi tidak dapat dihindari sehingga waktu pelayanan menjadi lama. Data rekam medis yang masih disimpan secara konvensional dalam ratusan map di lemari bertingkat membuat pencarian data pasien menjadi lambat dan besar kemungkinan kurang akurat. Berdasarkan permasalahan yang ada, maka dikembangkanlah sebuah sistem informasi untuk menyimpan data rekam medik pasien puskesmas. Semua data rekam medik puskesmas yang sebelumnya disimpan secara manual akan dipindahkan ke sistem informasi yang dibangun yang juga mencakup proses otomasi alur pendaftaran ke poli yang diperlukan. Berbeda dengan sistem yang telah ada, sistem rekam medik ini juga dilengkapi dengan kartu pintar pribadi untuk masing-masing pasien dan terintegrasi dengan data pasien dari Badan Penyelenggaran Jaminan Sosial (BPJS) Kesehatan. Petugas cukup memindai kartu ini untuk mengakses data rekam medik pasien. Sistem ini dibangun dengan menggunakan pendekatan Waterfall sebagai metode pengembangan perangkat lunaknya. Dengan adanya sistem informasi rekam medis ini data pasien dapat disimpan dengan lebih efisien dan terhindar dari duplikasi data. Pasien yang datang ke puskesmas akan dapat terlayani dengan lebih cepat. Catatan riwayat kesehatannya juga dapat diketahui secara lengkap sehingga diagnosa dokter bisa menjadi lebih akurat. Aplikasi rekam medis terintegrasi untuk Upt puskesmas ini juga memudahkan proses pencarian data sehingga dapat meningkatkan kinerja pegawai puskesmas dalam melakukan pengolahan data rekam medis, dan juga obat-obatan. Selain itu resiko rusak, hilang, dan duplikasi data rekam medik pasien juga akan dapat diminimalisir. Lebih lanjut lagi, aplikasi rekam terintegrasi ini membuat laporan yang ditujukan kepada pimpinan menjadi lebih akurat.
\end{abstract}

Kata Kunci: sistem informasi terintegrasi, rekam medik, puskesmas, otomasi antrian, kartu pintar.

\begin{abstract}
Services at Puskesmas are often considered slow. The administrative process that is still done manually coupled with the large number of patients makes the queue unavoidable so the service time becomes long. Medical record data that is still stored conventionally in hundreds of folders in multilevel cabinets makes searching patient data slow and most likely less accurate. Based on the existing problems, an information system was developed to store the medical records of Puskesmas patients. All Puskesmas medical record data that were previously stored manually will be transferred to the information system built which also includes the process of automation of the registration flow to the poly required. In contrast to the existing system, this medical record system is also equipped with a personal smart card for each patient and is integrated with patient data from the Health Social Insurance Agency (BPJS). Officers simply scan this card to access the patient's medical record data. This system was built using the Waterfall approach as a software development method. With this medical record information system, patient data can be stored more efficiently and avoid data duplication. Patients who come to the Puskesmas will be served faster. His medical history can also be known in full so that the doctor's diagnosis can be more accurate. This integrated medical record application for Upt Puskesmas also facilitates the process of finding data. So that it can improve the performance of Puskesmas staff in processing medical record data, as well as medicines. Besides the risk of damage, loss, and duplication of patient medical record data will also be minimized. Furthermore, this integrated record application makes reports addressed to leaders more accurate.
\end{abstract}


Keywords: integrated information systems, medical records, puskesmas, queue automation, smart cards.

\section{PENDAhuluan}

Puskesmas merupakan kependekan dari Pusat Kesehatan Masyarakat yaitu fasilitas pelayanan kesehatan yang menyelenggarakan upaya kesehatan masyarakat dan upaya kesehatan perseorangan tingkat pertama, dengan lebih mengutamakan upaya promotif dan preventif,untuk mencapai derajat kesehatan masyarakat yang setinggi-tingginya di wilayah kerjanya (Indonesia, 2014). Puskesmas merupakan badan pemerintah yang memberikan pelayanan kesehatan di tingkat kecamatan. Sebagai pilar pelaksana program-program kesehatan pemerintah pada tingkat tersebut, puskesmas bertanggung jawab memberikan pelayanan yang optimal kepada masyarakat.

Berkenaan dengan hal tersebut maka diperlukan optimalisasi pelayanan di berbagai lini termasuk di antaranya adalah dari segi teknologi sistem informasi. Sistem Informasi Puskesmas adalah suatu tatanan yang menyediakan informasi untuk membantu proses pengambilan keputusan dalam melaksanakan manajemen puskesmas dalam mencapai sasaran kegiatannya (Indonesia, 2014). Sistem ini digunakan untuk mencatat data kesehatan setiap pasien.

Meski di beberapa daerah telah dikembangkan sistem informasi puskesmas yang mencatat data pasien (Cahyanti \& Purnama, 2012), (Nugroho, Fitriasih, \& Widada, 2015), (Ramadhan et al., 2008), (Syukron \& Hasan, 2015), (Wibisono \& Munawaroh, 2012), (Sundari, 2016) proses antrian dan pencatatan administrasi pada puskesmas pada umumnya saat ini masih secara manual. Pasien yang datang harus mengambil nomor antrian, kemudian petugas akan mencari data rekam medik yang disimpan dalam lemari. Setelah itu pasien diarahkan ke poli yang dituju lalu setelah pemeriksaan pasien akan antri mengambil obat. Kondisi seperti ini sangat tidak efisien. Hal ini dapat menimbulkan permasalahan baru jika terdapat pasien yang kurang sabar, sehingga dikhawatirkan timbul opini buruk mengenai pelayanan di puskesmas. Disamping itu, pencatatan rekam medik secara manual memiliki kekurangan diantaranya terdapat identitas ganda, catatan hilang, sehingga riwayat kesehatan pasien tidak terekam dengan baik. Lebih lanjut, dengan jumlah file yang terlampau banyak pada ruangan yang sangat sempit, dapat mengganggu produktivitas karyawan.

Berdasarkan kondisi yang telah diuraikan, maka sangat mungkin jika dibutuhkan peran teknologi untuk mengatasi permasalahan tersebut. Oleh karena itu dikembangkanlah suatu sistem informasi rekam medik terintegrasi di lingkungan puskesmas. Secara garis besar, perbedaan sistem informasi ini dengan yang telah ada yaitu bahwa sistem ini mengintegrasikan beberapa fungsi yang ada di puskesmas, meliputi pendaftaran antrian pasien, poli, pencatatan rekam medik yang terintegrasi dengan layanan BPJS (Badan Penyelenggara Jaminan Sosial) Kesehatan, dan pengambilan obat sesuai resep.

Harapannya dengan dikembangkannya sistem informasi terintegrasi ini, operasional puskesmas akan lebih efektif dan efisien. Meningkatnya kecepatan dalam pencarian data akan mempercepat antrian dan juga meningkatkan efisiensi tenaga kesehatan dalam menangani pasien sehingga lebih banyak pasien yang dapat dilayani dalam satu hari. Hal ini tentu akan menambah keuntungan bagi puskesmas.

Dengan adanya sistem ini maka terjadinya duplikasi data dapat dihindari sehingga tidak ada satu pasien dengan lebih dari satu data rekam medis. Tenaga medis dapat melihat riwayat kesehatan pasien secara detil dan menyeluruh. Hal ini tentu menunjang dalam pembuatan diagnosa yang lebih tepat. 
Lebih jauh lagi, dengan proses digitalisasi data pasien ini maka tidak lagi dibutuhkan ruangan khusus yang cukup luas untuk lemari penyimpanan data sehingga menghemat dari sisi spasial. Dalam segi operasional pelaporan tentu juga akan terbantu dengan terwujudnya sistem ini di mana fitur pelaporan akan menjadi komponen wajib dalam pengembangannya.

\section{METODOLOGI}

Pengembangan perangkat lunak dilaksanakan selama 12 bulan dengan model pengembangan Waterfall. Metode pengembangan perangkat lunak (Software Development Life Cycle) sangat penting untuk pengembangan perangkat lunak dengan cara yang sistematis sehingga sistem dapat selesai dalam jangka waktu yang ditentuakn dengan kualitas yang baik. Metode Waterfall ini merupakan salah satu metode pengembangan perangkat lunak di mana gambaran detil kebutuhan pengguna telah diketahui sebelum proses perancangan. Metode ini merupakan metode sekuensial dimana suatu tahapan harus selesai terlebih dahulu sebelum tahapan berikutnya dilaksanakan sehingga tidak ada fase tahapan yang tumpang tindih atau bersamaan (Balaji, 2012). Kelebihan dari metode ini antara lain:

a. mudah dipahami dan diimplementasikan

b. lebih populer

c. definisi dibuat sebelum mendesain, dan desain dibuat sebelum implementasi

d. sangat sederhana

e. sangat cocok untuk produk yang stabil dengan struktur yang jelas (Alshamrani \& Bahattab, 2015).

Uji coba dan tahapan dokumentasi dilaksanakan di akhir siklus. Detil setiap tahapan dijelaskan sebagai berikut:

a. Survei dan Analisis Kebutuhan

Survei dilakukan dengan tujuan untuk memahami kebutuhan-kebutuhan Puskesmas akan sistem informasi yang akan dibangun. Hasil survei akan dianalisis untuk mendapatkan spesifikasi kebutuhan sistem.

b. Perancangan dan Pembangunan Sistem Informasi

Sistem informasi rekam medik dirancang dan dibangun pada fase ini sesuai dengan hasil survei dan analisis yang telah dilakukan sebelumnya.

c. Uji Coba Sistem

Sistem yang telah dibangun selanjutnya akan diuji coba dan diperbaiki apabila terdapat kesalahan atau galat yang ditemukan.

d. Dokumentasi

Pada tahap ini dilakukan pencatatan terhadap semua fungsi atau fitur yang telah dibangun. Catatan tersebut kemudian dituangkan dalam buku petunjuk penggunaan sistem.

e. Migrasi Data

Migrasi data dilakukan untuk memindahkan data rekam medik pasien yang sebelumnya disimpan secara manual ke dalam sistem yang dibangun.

f. Monitoring dan Evaluasi

Operasional sistem akan dimonitor secara berkala untuk memastikan sistem tersebut digunakan dengan baik serta untuk membimbing pihak Puskesmas jika terdapat permasalahan yang ditemui pada saat operasional. 


\section{HASIL DAN PEMBAHASAN}

\subsection{Analisis Kebutuhan}

Untuk membantu proses analisis kebutuhan dibuatlah diagram Use Case yang nantinya dapat menjadi dasar perancangan fitur-fitur utama dalam sistem. Use Case diagram sebagai alat pemodelan kebutuhan memainkan peranan penting dalam menjelaskan kebutuhan dari suatu sistem. Ia menjadi alat komunikasi di antara pengembang dan calon pengguna (stakeholder) untuk memahami apa saja kebutuhan dari suatu sistem (Shen \& Liu, 2003). Diagram Use Case ditunjukkan oleh Gambar 1.

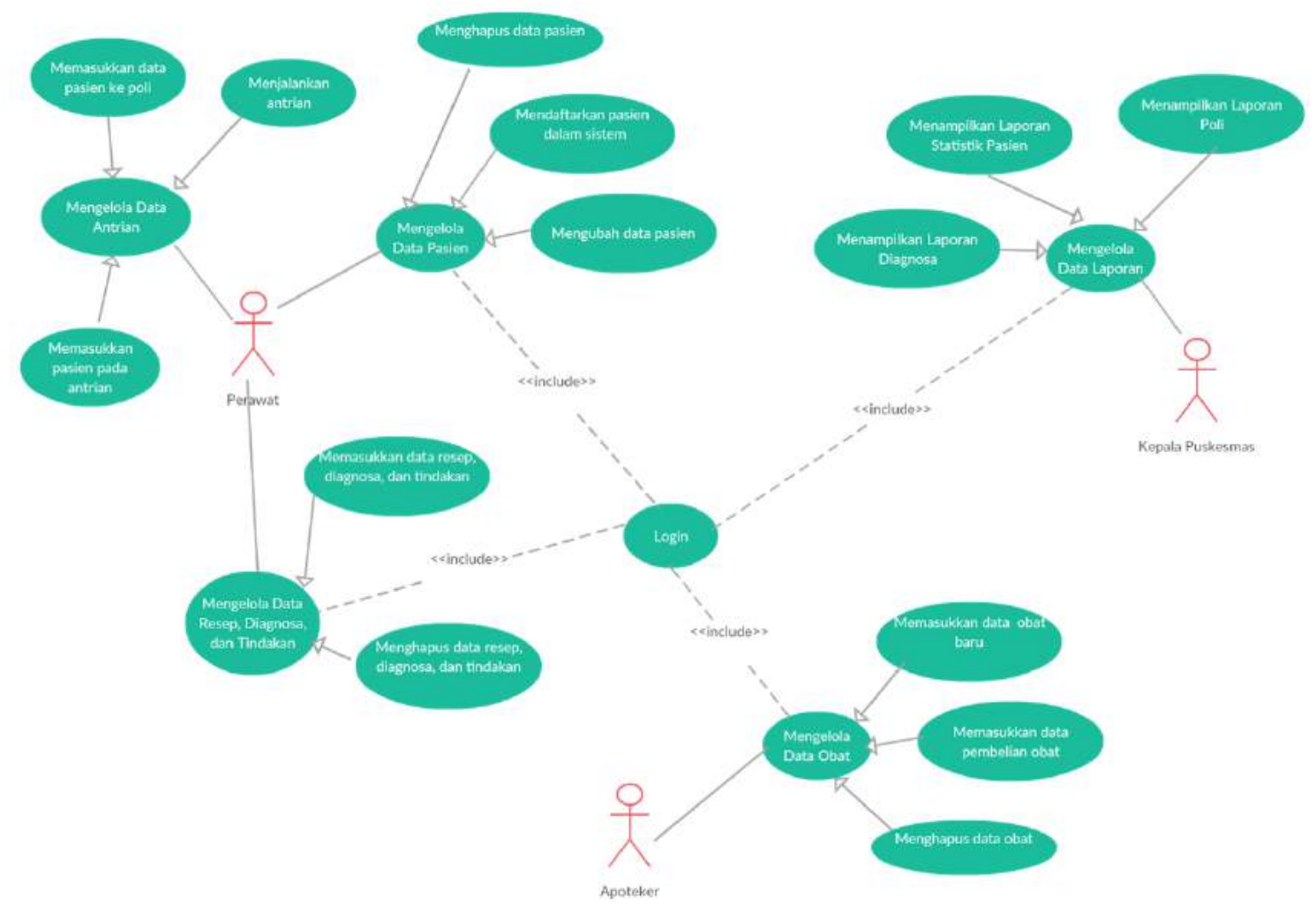

Gambar 1. Diagram Use Case

Berdasarkan permasalahan yang ada, maka solusi yang ditawarkan pada program ini adalah dengan membangun sebuah sistem informasi terintegrasi untuk menyimpan data rekam medik pasien Puskesmas-Puskesmas. Semua data rekam medik Puskesmas yang sebelumnya disimpan secara manual akan secara bertahap dipindahkan ke sistem informasi yang dibangun. Sistem informasi tersebut nantinya juga dihubungkan dengan bagian loket pendaftaran untuk pengelolaan antrian dan pengambilan obat. Pasien yang datang cukup menunjukkan kartu pasiennya di loket registrasi, poli, serta loket obat untuk dipindai sehingga dapat diproses secara otomatis.

Dengan adanya sistem informasi rekam medik ini diharapkan pelayanan Puskesmas dapat menjadi lebih baik dan efisien. Pasien yang datang ke Puskesmas akan dapat terlayani dengan lebih cepat. Catatan riwayat kesehatannya juga dapat diketahui secara lengkap sehingga diagnosa dokter bisa menjadi lebih akurat. Selain itu resiko rusak, hilang, dan duplikasi data rekam medik pasien juga akan dapat diminimalisir. 


\subsection{Rancangan Arsitektur}

Sistem informasi terintegrasi akan dikembangkan sebagai sebuah aplikasi web. Aplikasi web yang dibangun nantinya mempunyai beberapa fungsi dasar, yaitu untuk pendaftaran pasien di loket registrasi, menampilkan pencatatan data rekam medik pasien, serta untuk pendaftaran dan pengambilan obat. Sistem informasi ini dipasang pada sebuah server yang terhubung dengan jaringan komputer puskesmas.

Saat pasien datang, pasien menyerahkan kartu pasien yang dibawanya ke loket registrasi untuk didaftarkan ke poli yang dituju dengan cara memindai kartu dengan menggunakan barcode scanner yang terhubung dengan komputer puskesmas. Sistem kemudian menampilkan informasi medis pasien yang terhubung dengan data terpusat dari BPJS Kesehatan. Kemudian pasien akan otomatis terdaftar pada antrian poli tersebut. Setelah menunggu hingga gilirannya datang, pasien menuju poli tujuan dan menyerahkan kartunya kembali ke dokter. Dokter kemudian dapat melihat histori rekam medik pasien tersebut dengan memindai nomor barcode pada kartu pasien. Sistem akan otomatis menampilkan data rekam medik pasien tersebut. Setelah dokter selesai memeriksa dan mendiagnosis pasien tersebut, maka dokter atau perawat memasukkan data rekam medik seperti diagnosa, resep, dsb ke dalam sistem. Pasien kemudian dapat menuju ke loket obat puskesmas untuk mendaftarkan serta mengambil obat sesuai resep dokter tersebut.

Untuk menjaga keamanan dan kerahasiaan data pasien, maka sistem informasi rekam medik hanya dapat diakses di komputer-komputer yang sudah ditentukan dengan menggunakan akun masing-masing petugas Puskesmas dan dokter yang berwenang. Petugas Puskesmas dan Dokter juga harus menjaga kerahasisan akunnya masing-masing. Data rekam medik juga harus ditutup setelah dokter selesai melihat data tersebut. Gambaran mengenai implementasi sistem tersebut dapat dilihat pada Error! Reference source not found..

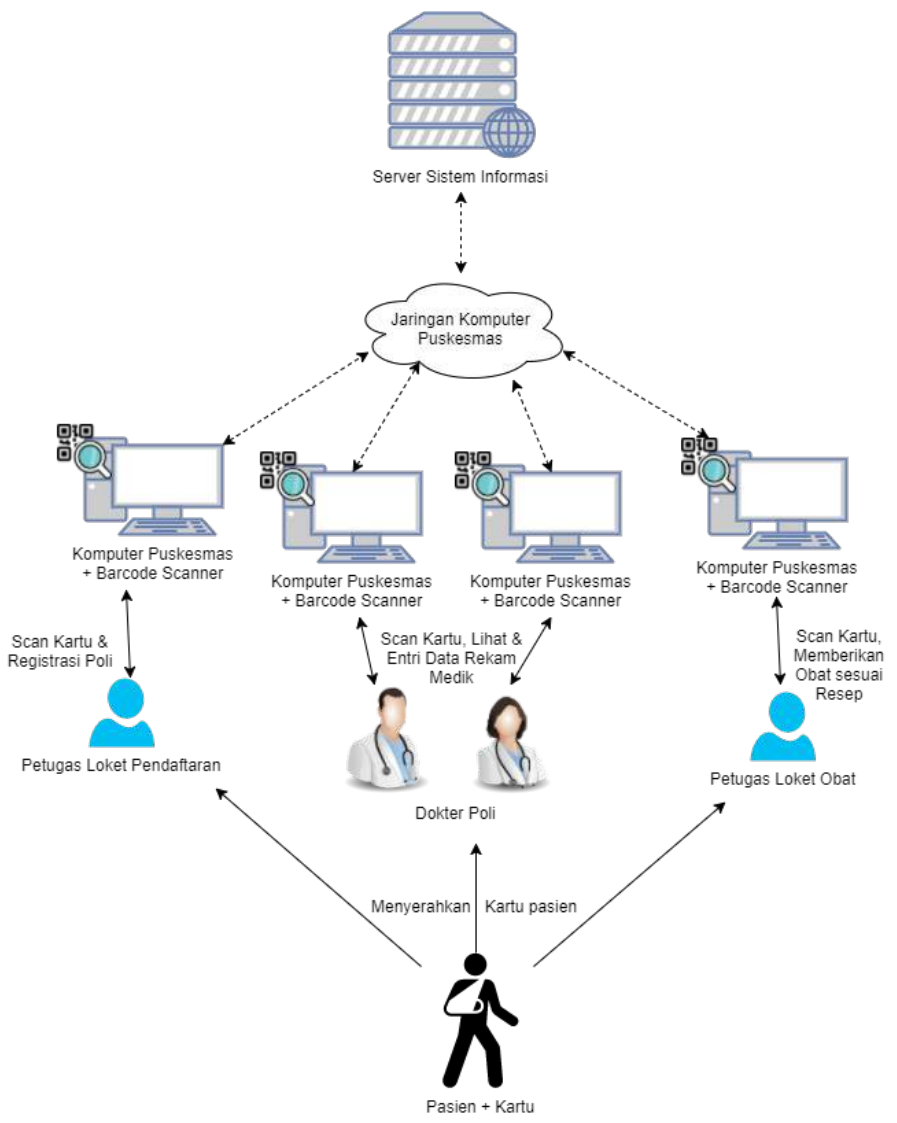

Gambar 2. Rancangan Arsistektur 


\subsection{Desain Basis Data}

Berdasar hasil analisis kebutuhan dan perancangan arsitektur sebelumnya, dibuatlah desain basis data guna memenuhi kebutuhan dan mengakomodir proses bisnis mitra. Desain basis data tersebut disajikan oleh Error! Reference source not found.

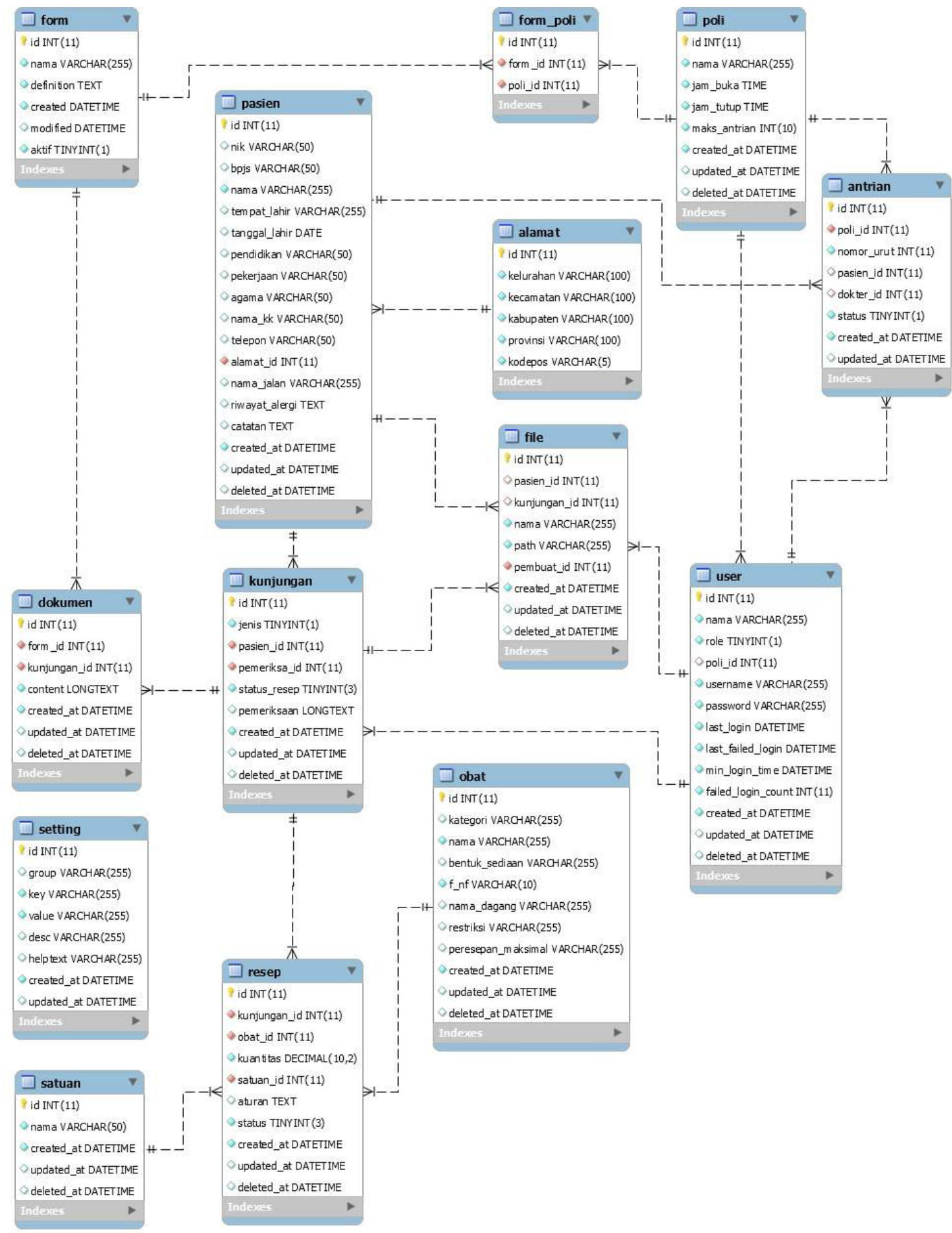

Gambar 3. Desain Basis Data 


\subsection{Hasil Pengembangan Sistem}

Setelah basis data terbentuk, dikembangkanlah sistem informasi sesuai dengan kebutuhan mitra. Tampilan dari beberapa halaman sistem yang dihasilkan disajikan pada Gambar 4-9 berikut.

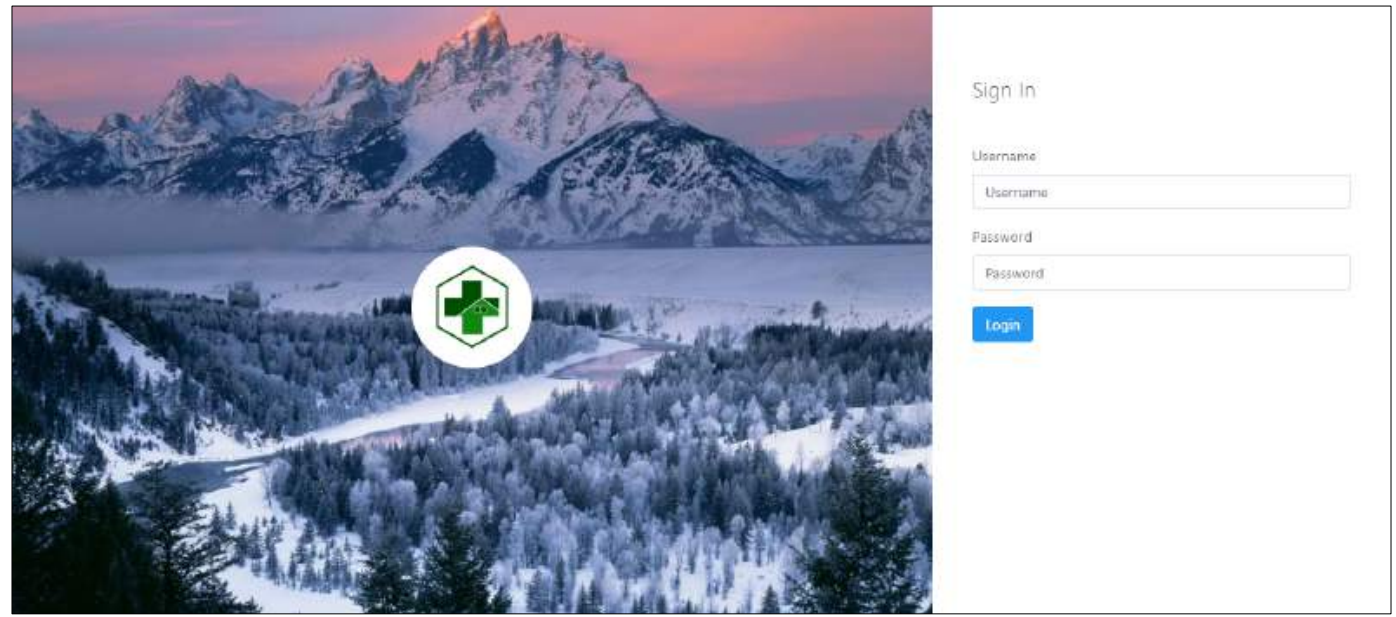

Gambar 4. Halaman Login

Dashboard

Banyak Pasien

: : 20

Banyak Dokter

$\therefore$

Banyak Poll

Kunjungan Bulan ini

2 arang

苗

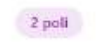

5

ติ

붕

*

s.

a

$\leftrightarrow$

Gambar 5. Halaman Dashboard

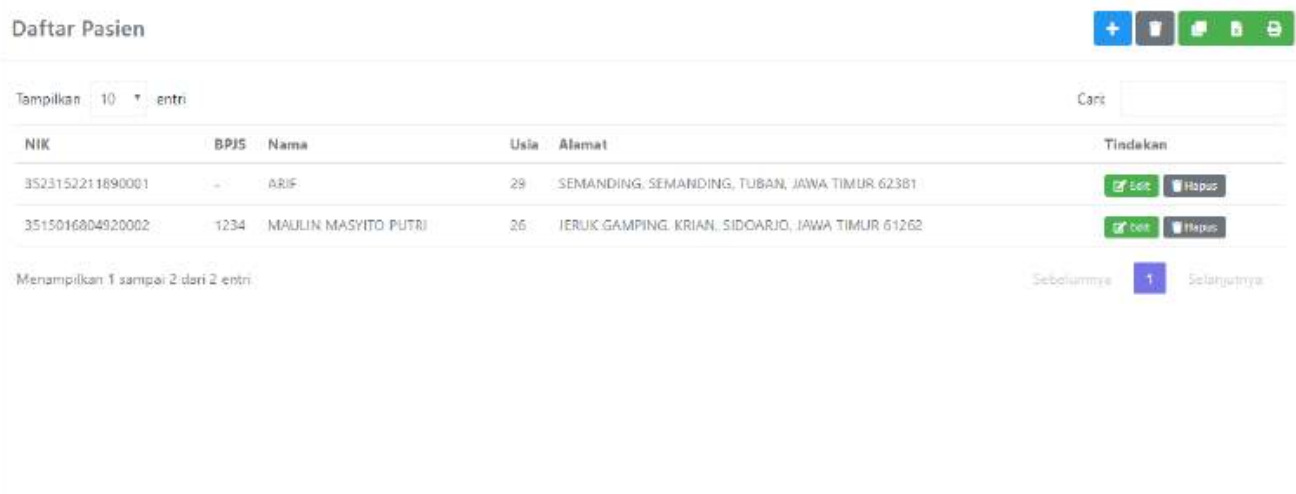

Gambar 6. Halaman Daftar Pasien 


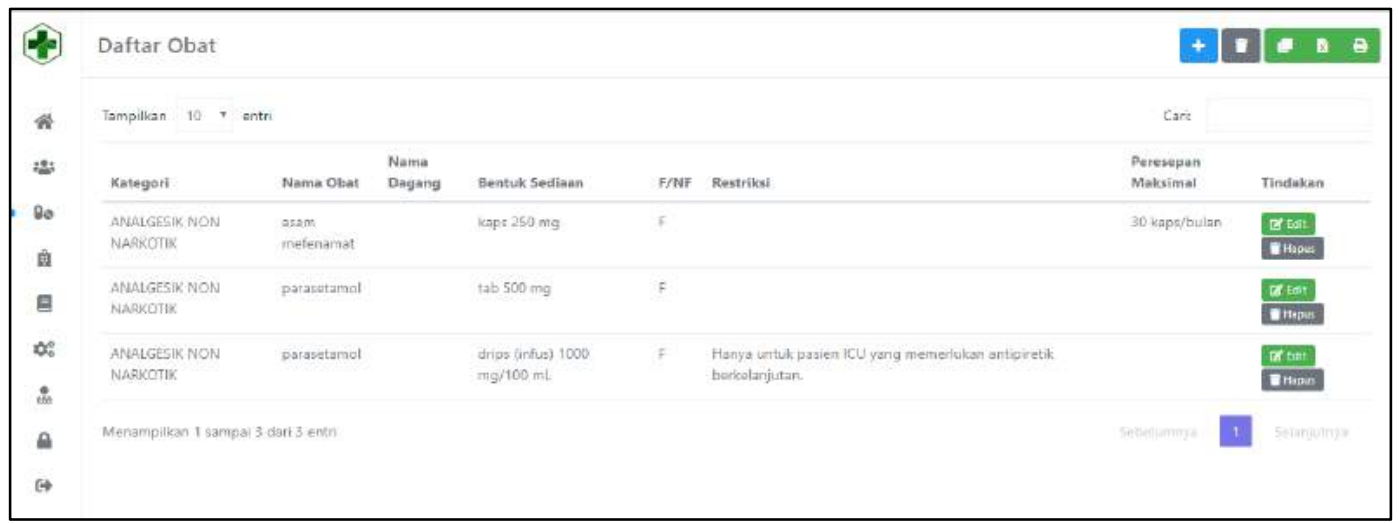

Gambar 7. Halaman Daftar Obat

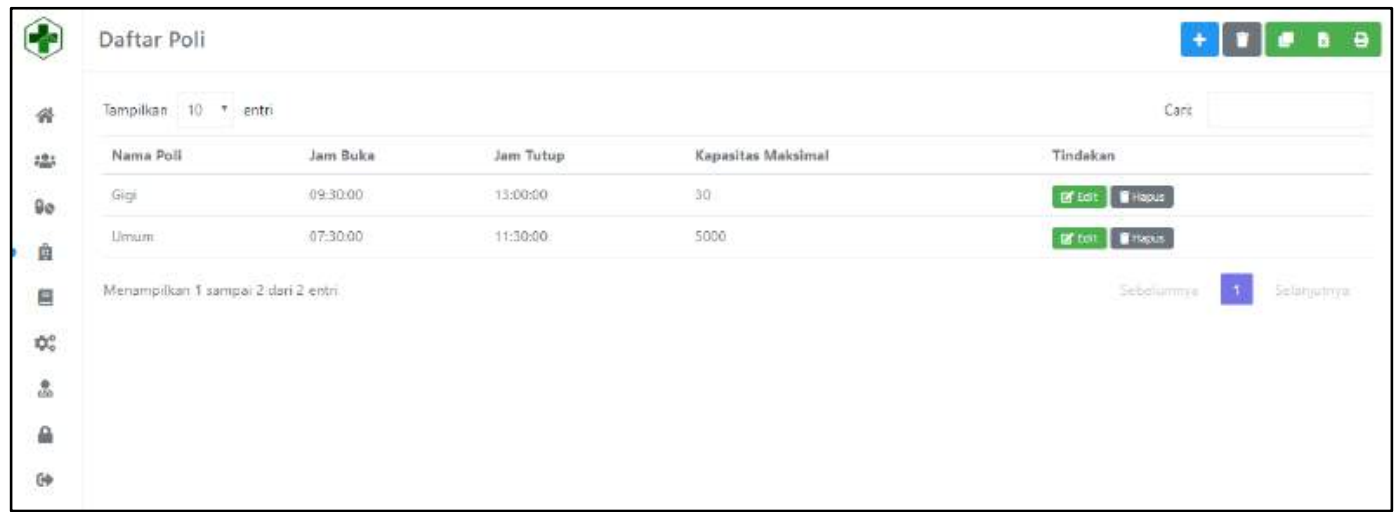

Gambar 8. Halaman Daftar Poli

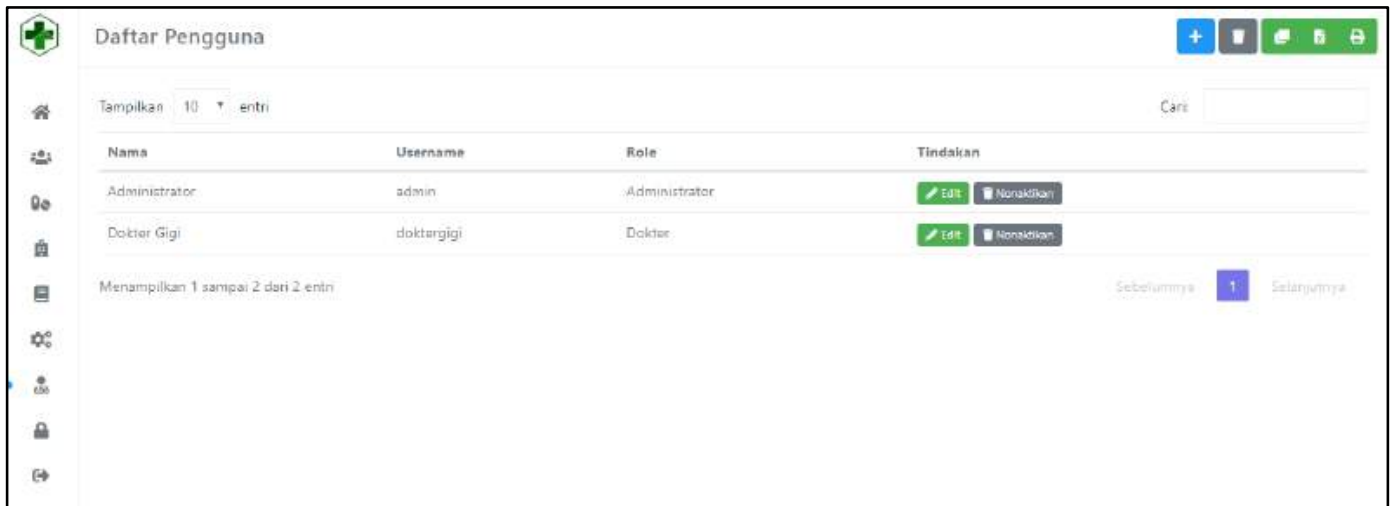

Gambar 9. Halaman Daftar Pengguna

\section{KESIMPULAN}

Dengan adanya sistem informasi rekam medis ini data pasien dapat disimpan dengan lebih efisien dan terhindar dari duplikasi data. Aplikasi rekam medis terintegrasi yang telah dikembangkan juga memudahkan proses pencarian data, meningkatkan kinerja pegawai puskesmas dalam melakukan pengolahan data rekam medis, dan juga obat-obatan, serta membuat laporan yang ditujukan kepada pimpinan menjadi lebih akurat. Sebuah puskesmas yang mempunyai jumlah pasien cukup banyak hendaknya menggunakan sistem informasi rekam medik semacam ini agar dapat mengoptimalkan pelayanannya. Setelah aplikasi ini dipasang pada sistem 
di puskesmas, sebaiknya dilakukan sosialisasi atau pelatihan yang menyeluruh terhadap semua lini pengguna di puskesmas agar penggunaan sistem ini dapat berjalan dengan optimal.

\section{DAFTAR PUSTAKA}

[1] Alshamrani, A., \& Bahattab, A. A Comparison Between Three SDLC Models Waterfall Model, Spiral Model, and Incrementa1/Iterative Model. I International Journal of Computer Science Issues, 12(1), 106-111. 2015.

[2] Balaji, S. Waterfall vs V-Model vs Agile: A Comparative Study on SDLC. 2(1), 26-30. 2012.

[3] Cahyanti, A., \& Purnama, B. 2012. Pembangunan Sistem Informasi Manajemen Puskesmas Pakis Baru Nawangan. Journal Speed - Sentra Penelitian Engineering Dan Edukasi, 4(4), 17-21. 2012. https://doi.org/10.3112/SPEED.V4I4.893

[4] Indonesia, K. K. R. 2014. Peraturan Menteri Kesehatan Republik Indonesia Nomor 75 Tahun 2014. 2014.

[5] Nugroho, B., Fitriasih, S. H., \& Widada, B. Sistem Informasi Rekam Medis Di Puskesmas Masaran I Sragen. Jurnal Teknologi Informasi Dan Komunikasi (TIKomSiN), 3(2). 2015. https://doi.org/10.1016/B978-0-7216-0252-3.50005-9

[6] Ramadhan, R., Angga, T. O., Cofriyanti, E., Si, S., Hartati, E., \& Kom, M. Sistem Informasi Rekam Medis Rawat Inap dan Rawat Jalan Pada Puskesmas Sukajadi. Medical Informatic System, 1(1), 1-10. 2008.

[7] Shen, W., \& Liu, S. Formalization, Testing and Execution of a Use Case Diagram. International Conference on Formal Engineering Methods, 68-85. 2003.

[8] Sundari, J. Sistem Informasi Pelayanan Puskesmas Berbasis Web. Indonesian Journal on Software Engineering, 2(1), 45-49. 2016.

[9] Syukron, A., \& Hasan, N. Perancangan Sistem Informasi Rawat Jalan Berbasis Web Pada Puskesmas Winong. Jurnal Bianglala Informatika, 3(1), 28-34. 2015.

[10] Wibisono, S., \& Munawaroh, S. Sistem Informasi Manajemen Puskesmas (Simpuskesmas) berbasis Cloud Computing. Jurnal Teknologi Informasi Dinamik, 17(2), 141-146. 2012. 